\title{
Eficácia simbólica da promessa em psicoterapia com adolescentes*1
}

\section{Symbolic effectiveness of the promise in psychotherapy with adolescents}

\author{
Hellen Fonseca de Sousa da Costa Vale*2 \\ Francisco Moacir de Melo Catunda Martins*3
}

Considerando a problemática da evasão de pacientes em clínicas-escola, somada à dificuldade de adesão que os adolescentes apresentam à psicoterapia, temos como objetivo neste estudo entender se o ato promissivo é efetivo para a manutenção do vínculo terapêutico e, consequentemente, para a continuidade da psicoterapia. Nesta pesquisa, observou-se que a maioria dos pacientes não estabeleceram o ato promissivo. O que nos permitiu concluir que a problemática da fase da adolescência, somada à não atenção dos terapeutas nas prioridades a serem seguidas e no modo de comprometimento dos adolescentes, promoveram um prejuizo diante da continuidade da psicoterapia.

Palavras-chave: Promessa. contrato. evasão. clínica, adolescência

*1 Artigo elaborado a partir da dissertação de mestrado "Promessa e terapia com adolescente. Estudo exploratório acerca da desistência no início de psicoterapia", sob a orientação de Francisco Martins no Programa de Mestrado e Doutorado em Psicologia da Universidade Católica de Brasília, 2015.

*2 Doutoranda pela Universidade Católica de Brasília - UCB (Brasília, DF, Br)

${ }^{* 3}$ Universidade Católica de Brasília - UCB (Brasília, DF, Br) 


\section{Adolescência e a clínica}

Etimologicamente a palavra adolescência tem sua origem no Latim "ad", que significa 'para' + "olescere" que quer dizer 'crescer'. Portanto, adolescência em seu sentido mais literal se traduziria em 'crescer para' ser adulto, cidadão e livre (Pereira \& Pinto, 2003). Do ponto de vista psicanalítico, Freud (1905/1980) não tratou de adolescentes e nem falava de adolescência. Mas trouxe questões relacionadas à puberdade e às manifestações pulsionais atreladas a esse segundo momento de manifestações sexuais que ocorrem após o período de latência. Sabemos com Freud (1905/1980) que a puberdade se apresenta pelo reaparecimento da pré-genitalidade, que é marcada pelo aumento quantitativo das pulsões que acontece ao final da latência. Portanto, após a impregnação da latência, o Édipo é retomado, pela adolescência, em uma dupla vertente: parricida e incestuosa. Por isso, as realizações alcançadas no sentido de controle interno das pulsões e inserção social, podem agora ser destinadas à desintegração, levando o adolescente a se perder em meio aos sintomas que impedem o crescimento progressivo para se tornar uma pessoa social completa.

Assim como Freud, entendemos que os caminhos da sexualidade e seus processos subjetivos provêm muito mais do meio e das relações estabelecidas do que somente do aparato biológico da puberdade. Entendermos também que as mudanças corporais/ biológicas mudam a forma de concebermos e diferenciarmos o modo de tratamento social para crianças e adolescentes. Podemos perceber que existe uma variabilidade no que diz respeito à pubescência. Na Amazônia, por exemplo, as jovens de 11 anos que menstruam são logo consideradas mulheres e têm vida sexual precoce, caso comparemos com a pubescência na Suécia que 


\section{ARTIGOS}

ocorre entre os 16 e 20 anos. Então, isso de certa maneira demonstra que o conceito de adolescência foi construído culturalmente e não é somente o fator biológico da menarca que marca tal entrada, no caso das meninas. Ou seja, é uma questão muito mais simbólica.

Aqui entendemos adolescência principalmente como um fenômeno intimamente ligado ao processo de reorganização do modo de ser, da moral, sexuação e agressividade. Ligado também ao processo cultural da atualidade e que passou a ocupar um lugar importante na visão de pesquisadores de diversas áreas do saber (psicólogos, sociólogos, antropólogos, pais, escolas etc.), tal fenômeno não poderia ficar de fora da clínica psicanalítica. Sobretudo quando se trata de atendimento de adolescentes em clínicas-escola por terapeutas iniciantes. O turbilhão ligado ao processo de reorganização psíquica do paciente adolescente, junto ao fato de o terapeuta não prestar a devida atenção ao modo de comprometimento do adolescente, pode trazer um prejuízo na vinculação terapêutica de sucesso que será a base para a adesão ao tratamento.

A situação de evasão de adolescentes em clínicas-escola é perpassada por diversos fatores que interferem na adesão, de acordo com Campezatto \& Nunes (2007), Cunha \& Benetti (2008), Jung (2013), Nash et al., (1965); Langs, (1973); Bosch, (1980); Ryan; Cicchetti, (1985) citados por Ceitlin \& Cordioli (2008). Dentre esses fatores, temos como principais, por parte do estagiário, a insegurança e ansiedade elevadas, principalmente nos primeiros encontros, provenientes da falta de experiência de psicoterapeutas iniciantes. Além disso, existe a dificuldade de os adolescentes manterem o compromisso contratual. De modo geral, as pesquisas apontam que a qualidade do vínculo estabelecido, a forma como se maneja o contrato e a disposição para a promessa do paciente e do terapeuta, são fatores responsáveis pelo sucesso ou fracasso da psicoterapia.

\section{Promessa e adolescência}

Como apresentamos anteriormente, a adolescência exige uma reorganização do psiquismo moral. Atualmente, parte dos jovens tem o ideal, mas não querem a obrigação; outra parte tem certas obrigações, mas o ideal está obstruído por sintomas. O que nos traz a reflexão: já que todo ideal implica uma promessa, sem ideal é possível a adesão à psicoterapia? Somente quem entende o que significa uma promessa é capaz de prometer e poderá se comprometer com certos atos futuros, inclusive o ato terapêutico. Firmar um 
compromisso em início de psicoterapia é primordial para o andamento do processo. É em cima de tal compromisso que o contrato terapêutico se estabelece sob o pilar da promessa. O tratamento somente se realiza se o contrato for estabelecido, acordado e aceito em ato. No entanto, não se trata de um contrato qualquer, como explicita Freud (1940[1938]/1969):

(...) Fazemos um pacto um com o outro. O Eu enfermo nos PROMETE a mais absoluta sinceridade, isto é, PROMETE colocar à nossa disposição todo o material que a sua autopercepção lhe fornece; garantimos ao paciente a mais estrita discrição e colocamos a seu serviço a nossa experiência em interpretar material influenciado pelo inconsciente. Nosso conhecimento destina-se a compensar a ignorância do paciente e a devolver a seu Eu o domínio de regiões perdidas de sua vida mental. Esse pacto constitui a situação analítica. (p. 188)

$\mathrm{Na}$ tradução literal da edição $(E S B)$ acima, nota-se que o tradutor optou por traduzir Vertrag por pacto; no entanto, a forma de Freud se expressar era simples e clara: ele ao pronunciar Vertrag, falava de algo mais relacionado ao contrato, a um compromisso e um acordo entre as partes. Além disso, quando o tradutor traz a palavra sinceridade, não contempla o termo correto. O termo mais próximo em alemão é retidão (vollste Aufrichtigkeit), que nos leva a pensar que a pessoa mesmo estando com raiva, continua comprometida.

Não é pacto, e não é sinceridade. O compromisso estabelecido entre paciente e terapeuta resulta no contrato. $\mathrm{O}$ tratamento somente se realiza se houver o estabelecimento desse compromisso com retidão. O compromisso nada mais é que uma promessa mutua, "prometer com".

Aprendemos com Freud (1912/2010) que a vida imita o vídeo e vice-versa. Isto é, o setting analítico é o espaço onde se apresentam comportamentos que acontecem no cotidiano da vida como ela é, assim como o que acontece dentro do setting pode influenciar no modo de ser do sujeito fora dele. Sendo assim, acreditamos que ajudar o adolescente a lidar com as questões contratuais, a prometer e cumprir com aquilo que foi prometido em um tratamento psicoterápico, poderá auxiliá-lo a lidar com a reorganização que a fase da adolescência exige sem abandonar a psicoterapia.

\section{Sobre o método}

A fim de investigarmos os primeiros encontros entre pacientes adolescentes e terapeutas iniciantes, procedemos com uma pesquisa exploratória 


\section{ARTIGOS}

acerca do ato promissivo e a escuta dos verbos modais. A pesquisa partiu da gravação de entrevistas iniciais de pacientes e estagiários de uma clínica-escola, situada no Distrito Federal, cuja identificação omitiremos por motivo ético. Optamos pela introdução de um gravador no setting psicoterápico em vez da inserção da pesquisadora na sala de espelho.

Optamos também por não expor os objetivos e o objeto de estudo da pesquisa antes que a mesma terminasse, com vistas a obter os menores atravessamentos possíveis, bem como guardar a ética da clínica intacta.

Ao longo de um semestre foram gravados os atendimentos de três estagiárias da única turma de estágio supervisionado do semestre, com ênfase na clínica psicanalítica com adolescentes. Também optamos por gravar e analisar as entrevistas iniciais de um terapeuta recém-formado em ambiente externo. Optamos pela gravação fora, em razão da dificuldade de mantermos a linearidade temporal dos pacientes com relação aos atendimentos. Ou seja, o não comprometimento dos adolescentes se traduziu no surgimento de um sintoma da própria pesquisa, dado que os adolescentes marcavam o primeiro encontro e não compareciam, e a maioria dos que compareciam se ausentava na sessão seguinte. Por fim, acabavam por desistir do processo antes mesmo que começasse.

Contudo, contamos com seis estagiárias na turma do primeiro semestre de 2015; três consentiram e conseguiram seguir com as gravações. As que consentiram chamaremos TA., TB. e TC. Nenhum dos pacientes que participaram das gravações esteve presente mais de três vezes nas sessões.

Procedemos com a análise das entrevistas de cinco duplas psicoterápicas. As entrevistas foram analisadas a partir do ponto de vista da teoria dos atos de fala promissivos de Searle (1969/1984) e da teoria dos verbos modais de Martins (2003). Atemo-nos precisamente aos atos compromissivos na tentativa de demarcar o complexo ato da promessa. A promessa é tomada como uma expressão de uma intenção futura, sendo que o compromisso, por sua vez, traz a implicação necessária de uma promessa. Cabe ressaltar que alguns atos de fala são acompanhados pela modalização, como os exemplos dos tipos de atos diretivo e promissivo do quadro abaixo que colocamos em negrito. No quadro de taxonomia dos atos de fala fica evidente que a modalização acompanha o promissivo. 
Quadro 1 - Taxonomia dos atos de fala

\begin{tabular}{|l|l|l|}
\hline \multicolumn{1}{|c|}{ Tipo de ato } & \multicolumn{1}{|c|}{ Definição } & \multicolumn{1}{c|}{ Exemplos } \\
\hline Diretivos & $\begin{array}{l}\text { Tentativas (em graus variados) } \\
\text { de levar o ouvinte a fazer algo }\end{array}$ & $\begin{array}{l}\text { Pedir, ordenar, mandar, } \\
\text { suplicar, rogar, } \\
\text { desafiar, aconselhar }\end{array}$ \\
\hline $\begin{array}{l}\text { Compromissos ou } \\
\text { promissivos }\end{array}$ & $\begin{array}{l}\text { Tem o propósito de comprometer } \\
\text { o falante a alguma linha de ação } \\
\text { futura }\end{array}$ & $\begin{array}{l}\text { Prometer, jurar, } \\
\text { comprometer-se, obrigar-se a }\end{array}$ \\
\hline
\end{tabular}

Fonte: Searle (1969/1984)

O proferimento de um ato de fala expressa um estado intencional correspondente: desejo, intenção, crença. Necessariamente é expressado o estado psicológico. Ou seja, não se pode fazer qualquer declaração sem que se expresse uma crença; não se pode fazer uma promessa sem expressar alguma intenção (Searle, 1983/1995). Na concepção da teoria dos atos de fala, o comprometer-se traz o sentido da obrigação. Devemos destacar que o sentido de um ato de fala se dá pelo contexto de sua emissão e que ele não deve ser garantido apenas pela estrutura morfológica, sintática ou sonora da fala. Sendo assim, a sinonímia dos verbos modais é de suma importância, já que o que nos interessa é o sentido e o significado da palavra falada.

\section{Resultados e discussões}

Entende-se que a promessa sustentada e levada às últimas consequências é o que esteia o dever e o obrigar-se. O comprometimento do adolescente com o terapeuta e do terapeuta com o adolescente, é a única forma possibilitadora de sustento da continuação de uma relação terapêutica. $\mathrm{O}$ saber prometer e sustentar sua promessa, para o adolescente, ajuda-o a caminhar para aquilo que podemos dizer que é um homem de bem.

\section{Quando a terapia não é uma necessidade}

Temos inicialmente o caso do adolescente R., que chega à psicoterapia a pedido da escola. Os pais não comparecem. É levado por uma tia, que promete fazer o que for necessário para que ele continue o tratamento. $\mathrm{O}$ adolescente deixa explícito que a demanda não é dele e que não necessita 


\section{ARTIGOS}

de tratamento. Não demonstra nenhum sofrimento manifesto. O sofrimento e a queixa são da tia, do pai, da escola. O problema são os outros, não existem conflitos internos, seus conflitos são externos.

Portanto, o adolescente julga não precisar de terapia, mesmo o ato promissivo do responsável não é suficiente para o acontecimento do ato promissivo do paciente. O querer da família não é suficiente para que ocorra o seu autoengajamento. Ele não quer, sendo assim, não promete. Neste caso, não acontece a promessa por parte do terapeuta.

\section{A descrença e a incapacidade de fazer promessas}

Em seguida temos o caso do adolescente E., em que a descrença, o desânimo, o desinteresse e a falta de perspectiva de futuro - de acordo com a queixa da mãe - o incapacitam a acreditar e fazer promessas. $\mathrm{O}$ adolescente chega com a queixa de se sentir desanimado. Justifica seu desinteresse por ter perdido a confiança na mãe, quando a mesma fez uma promessa no passado e não cumpriu.

Segue as falas do adolescente: "eu me sinto mais é desanimado", "ela disse que ia devolver se eu recuperasse a matéria, aí eu recuperei e ela não devolveu". Tais falas demonstram que E. entende o significado da promessa, ele se comprometeu com uma ação futura ao aceitar "ter de (dever)" recuperar suas notas na matéria a fim de retomar aquilo que era desejado. Renunciou à sua inatividade no intuito de tomar uma posição ativa para alcançar a nota necessária para se recuperar. No entanto, a mãe não cumpriu com o dever que lhe cabia; tal fato serviu, para E., como uma injunção para o seu não comprometimento com ações futuras.

Neste caso, a terapeuta inicia falando sobre o termo de consentimento livre e esclarecido e requisitando a presença dos responsáveis, antes mesmo de escutar o motivo que fez o adolescente vir naquele momento. Os responsáveis não comparecem. $\mathrm{O}$ adolescente não retorna mais aos atendimentos. $\mathrm{A}$ terapeuta faz uma promessa, mas demonstra estar muito mais preocupada com o seu dever do que com o devir do adolescente na psicoterapia. Sendo assim, não houve nenhum ato promissivo do adolescente na primeira sessão, logo, ele não compareceu mais aos atendimentos.

No caso do adolescente E. conclui-se que houve uma inversão de prioridades: primeiro temos a necessidade, depois a demanda e, por último, o desejo. Então, o querer prometer deve ser alcançado primeiro e em seguida viriam as formalizações. Neste caso, devemos pensar como Rubem Alves 
(2008), em seu livro As melhores crônicas, fala sobre o rito do casamento. "Não é o amor que faz um casamento. São as promessas". Em seguida diz: "O futuro há de ser da forma como o presente o desenhou. Para isso, os contratos. E a substância dos contratos são as promessas" (p. 127). Deste modo, a clínica psicanalítica se torna uma tarefa similar ao casamento, quando também deve ser sustentada através da promessa perpetrada. Primeiro a promessa, depois a transferência. De outro modo, a clínica vira um casamento obrigado.

\section{Como prometer sem antes existir?}

O terceiro caso analisado foi da adolescente C., que foi mais um caso significativo de não comprometimento por parte do adolescente. C. é uma adolescente de 12 anos, que chega acompanhada da mãe com a queixa de se sentir muito ansiosa, de ter sintomas de pânico, tontura, tremores, sudorese, dificuldades de dormir à noite, e por isso se sente muito sonolenta durante o dia. De acordo com a mãe, C. tem problemas de saúde desde os cinco anos; foi diagnosticada com um tipo de hipoglicemia reativa com muito carboidrato no sangue. Não pode comer qualquer alimento.

Mãe e filha chegam ao primeiro atendimento com 40 minutos de atraso. A mãe se justifica dizendo que foi por causa da chuva. A terapeuta se apresenta como estagiária da clínica e já inicia enquadrando e trazendo questões relacionadas ao setting. Fala que o atendimento tem a durabilidade de 50 minutos, sinalizando o atraso e o restante do tempo que poderá escutá-las, introduzindo assim o contrato. Ato seguinte, lê todo o termo de consentimento livre esclarecido e pergunta se ambas querem assinar. Após a exposição de algumas regras contratuais, a terapeuta inicia com uma pergunta sobre o motivo que levou a mãe a buscar por um acompanhamento psicológico para a sua filha.

A mãe fala o tempo todo e quase não dá à filha tempo oportunidade de falar. Relata que com nove anos o problema de glicemia da filha aumentou. Tal fato ocorreu logo depois que descobriu que seu pai biológico não era o pai que ela conheceu.

Cabe ressaltar que a paciente $\mathrm{C}$., está passando pela crise da adolescência que, neste caso, compreende a dificuldade em relegar a parte infantil a um segundo plano e ir em busca de uma separação dos laços objetais antigos. C. apresenta dificuldade de renunciar aos objetos de amor edípicos em prol de possibilitar o encontro relacional com outros objetos amorosos não incestuosos. Em início de uma adolescência dita "normal", esse processo de 


\section{ARTIGOS}

desinvestimento libidinal provoca mudanças que podem levar a uma sensação de abandono pelo adolescente.

No entanto, podemos constatar que o Eu da adolescente busca proteger sua integridade pelo ato defensivo de não renunciar a algo da ordem do primário. Sendo assim, a paciente regride psiquicamente, voltando-se para o desejo de um estado simbiótico com a mãe. Eis a fala da mãe: "Ela não quer desgrudar de mim, às vezes eu falo: desce filha, vai brincar, vai ficar um pouco com a sua avó, mas ela não quer, ela não vai”.

De certa forma a mãe colabora para que o processo de separação não tome o seu rumo. Durante a sessão a paciente quase não se expressa, e, quando tenta, a mãe atravessa a fala da filha e responde por ela. A filha não consegue se posicionar. A mãe não dá espaço para isso. Os atos de fala da filha foram confirmando, em sua maioria, a fala da mãe. Assim, a adolescente não existe.

Importante notar que o atendimento teve a durabilidade de mais 55 minutos após a chegada da paciente. Mais uma vez, temos o problema da inversão de prioridades. Antes do acolhimento e do estabelecimento do vínculo, a terapeuta iniciou o contato pelas regras contratuais normativas. As preocupações iniciais deveriam situar-se em contraposição da ocorrência anterior, isto é, primeiramente o acolhimento, depois o vínculo, em seguida as promessas mútuas, só depois o estabelecimento das regras consensuais e, por último, as regras normativas. As regras normativas são mais institucionais, impessoais, ideológicas. Já as regras consensuais implicam a intimidade entre terapeuta e paciente, o amor sublimado fazendo a lei interna da terapia, o estilo, o caminho da cura. No consensual é que aparece a pessoa, o jeito de ser, a forma com que cada um se posiciona. Iniciar um primeiro encontro com a introdução das regras normativas não é indicado para terapias não tecnicistas.

Esse caso demonstra que apesar de a mãe pedir ajuda, dizendo que não sabe lidar com a situação e que gostaria de mudar a relação com a filha, o primeiro encontro serviu mais para uma catarse. A mãe simbolicamente vomita, e à filha lhe resta sentir: náuseas, insônia, tontura e sudorese.

Percebemos, então, que a queixa era da mãe, o desejo era do médico e a dor da adolescente. Sendo que, inevitavelmente, o sofrimento é a única forma da paciente existir. Muito embora o problema de C. seja tido pela mãe como algo grave, mesmo sabendo que o problema emocional pode agravar-se mais ainda, ela não faz nenhum ato promissivo. A filha também não. A terapeuta não finaliza as questões contratuais introduzidas no início do atendimento $\mathrm{e}$ também não faz nenhum ato de fala promissivo. Mãe e filha não retornam aos atendimentos. 


\section{Quando a promessa é possível, mas os pais sabotam}

B. é um adolescente que efetiva seu querer em ato e busca por uma psicoterapia. Ele demonstra engajamento pessoal e desejo de percorrer um processo terapêutico. Então, ao dizer: "quero ajuda para melhorar a ansiedade", o adolescente expressa uma intenção de se livrar de seus sintomas. Assim, corrobora a ideia de que a promessa é uma expressão de intenção, de acordo com Searle (1983/1995).

B. comparece ao primeiro atendimento acompanhado da mãe. Pediu por conta própria para procurar um psicólogo com a queixa de ficar tenso por estar ao lado de pessoas. Relata ter sofrido episódio de depressão recentemente. Fala sobre ideações suicidas recorrentes. No ano anterior chegou a fazer duas tentativas de autoextermínio. Fez acompanhamento com psiquiatra e diz que a medicação o ajudou um pouco.

O paciente B. tomou a iniciativa de procurar um psicólogo, após ter resolvido se afastar da igreja por conta de ter tido a curiosidade de apreender sobre "outras verdades" (sic). Diz ter começado a questionar as pessoas, a Igreja, o pastor, a Bíblia.

A crise edípica de B. transborda para o campo religioso apresentando-se na descrença na lei de Deus ou na lei do pai, já que para Freud, Deus é símbolo do pai. Por isso a conversão religiosa ou abandono da religião na adolescência ocorre com facilidade.

Neste caso, pode-se perceber que teríamos todas as questões positivas que poderiam contribuir para uma boa vinculação e efetivação de um tratamento. O paciente busca por ajuda sozinho, ele pede: "Quero ajuda para melhorar a ansiedade"; tem uma transferência anterior positiva com a psicanálise: "Acredito na teoria de Freud, li e gostei da teoria do Id, Ego e Superego", "Busquei por psicoterapia porque é ciência"; tem uma demanda clara para acompanhamento, com sintomas de uma neurose obsessiva de ideais altos: "Quero ser cientista e fazer grandes descobertas", "Não acredito mais em religião nem em Deus, só acredito no que eu possa ver", "Não me interesso por coisas de adolescentes, não me interesso por sexo, nunca namorei"; demonstra desejo de melhorar: "Nem sempre é bom ficar sozinho"; acredita que possa ser ajudado: "Sei que isso não é algo físico". Demonstra estar imbricado naquilo que chamamos de promessa, já que traz um desejo de realizar planos futuros: "Quero ser cientista e fazer grandes descobertas", esta frase evidencia que B. prenuncia uma ação futura. O querer ser evidencia o seu ideal de Eu. No entanto, o paciente comparece apenas a mais duas sessões.

Conclui-se que o adolescente B. faz afirmações que expressam sua crença e enunciam uma intenção. No entanto, não consegue sustentar seu 


\section{ARTIGOS}

querer. Os pais não se engajam no tratamento e se recusam a perceber a gravidade do caso do filho. Ademais, a mãe que o acompanha no primeiro encontro não faz nenhum ato promissivo. O filho, mesmo predisposto a prometer, demonstrando seu querer, sua intenção e sua transferência inicial com a psicanálise, também não produz nenhum ato promissivo.

Os verbos que o adolescente $\mathrm{B}$. expressou, indicam que seu querer vai no sentido de responsabilizar-se, ousar, tomar para si a terapia. Ele é uma pessoa típica para fazer terapia, é um adolescente engajado. Contudo, neste caso, o problema do prometer não é dele e sim dos pais que não se comprometem, não se engajam.

O adolescente não se configura como um sujeito pleno em seu querer, não tem respaldo social, financeiro e biológico para isso. Sendo assim, ele não consegue sustentar o seu querer sozinho, necessita da ajuda de terceiros e do comprometimento dos pais para que seu ato promissivo se efetue como tal. Este caso evidenciou que é necessário um engajamento e comprometimento dos familiares (pais ou responsáveis), para que a promessa possa se efetivar em ato. Por essa razão, na clínica adolescente exige-se um manejo específico nas primeiras entrevistas, um manejo que vá para além da relação terapêutica com o paciente, abrangendo também a família.

\section{Quando o ato promissivo sustenta a terapia}

No quinto e último caso analisado, temos o ato promissivo que sustenta a psicoterapia. É o caso da adolescente N., que foi acompanhada pelo terapeuta recém-formado em consultório particular. A adolescente N. também vai em busca de psicoterapia por vontade própria. Ela diz não estar aguentando mais ter sintomas depressivos, falta de motivação e desinteresse em fazer coisas que gostava de fazer.

Com N. foram gravadas três sessões seguidas. No primeiro contato ela comparece sozinha ao encontro com o psicólogo. No segundo, a dupla combina que $\mathrm{N}$. deve levar a mãe, e ela assim o faz. No terceiro, N. retorna novamente sozinha. Em seguida não foram feitas mais gravações pelo fato de o terapeuta ter de deixar a clínica por motivos pessoais e encaminhar a paciente N. para um outro profissional.

No primeiro encontro a paciente traz queixas e sintomas como mal-estar, tristeza, falta de ânimo e desespero. Recebidas as queixas, o terapeuta escuta e acolhe a dor da adolescente. Faz um movimento de empatia, não introduz questões contratuais e se abstém de fazer interpretações de qualquer tipo. 
Ressalta a atitude da adolescente de buscar por ajuda sozinha, e faz atos de fala em sua maioria diretivos e assertivos. Fica claro que a paciente estabeleceu uma aliança terapêutica positiva com o psicólogo.

Quando o terapeuta finaliza a sessão, pergunta a respeito da disponibilidade de horário para a continuação dos atendimentos; ela confirma e ao final diz: "Tá, esse horário eu posso, amanhã eu tenho que trazer a minha mãe, né?". A adolescente implicitamente produz, ao final, um ato de fala promissivo na primeira sessão. A assertiva em forma de interrogação demonstra que a adolescente se comprometeu com a ação futura, de voltar amanhã, tendo assumido o dever que é mais que uma promessa, é uma obrigação autoimputada de trazer a mãe.

$\mathrm{Na}$ sessão seguinte a paciente comparece juntamente com sua mãe. O terapeuta acolhe a queixa da mãe. Depois delineia o que é uma terapia. Faz um enquadramento. Ato seguinte, introduz o restante das questões contratuais. Em seguida, o terapeuta pergunta diretamente à mãe e à filha se elas concordam com a forma de contrato. Ambas dizem que sim. No entanto, não aconteceu nenhum ato promissivo da parte do terapeuta. Mas o ato promissivo da mãe e da paciente, corroborado pela boa vinculação terapêutica com o profissional, sustentam a continuidade da terapia, mesmo após a necessidade de o terapeuta se ausentar e a paciente ter de dar continuidade com outro profissional.

\section{Conclusões}

Pelas análises, pudemos concluir que, para que ocorra a aceitação do contrato em ato, exige-se uma sequência de prioridades a serem pensadas. Entendemos que existe uma sequência de atos a serem levados em conta no início de uma psicoterapia. Necessariamente, o acolhimento com escuta apropriada constitui a preocupação primordial. Em seguida indicamos o estabelecimento de vínculos, inclusive com os pais ou responsáveis. Depois as promessas mútuas que se espera sejam realizadas durante a exposição do contrato. Notamos que existe a necessidade de os pais ou responsáveis também fazerem promessas, no caso a de acompanhamento do adolescente. Ato contínuo, visamos a introdução das regras consensuais e, por último, as regras normativas e institucionais.

Porém, estes passos não foram seguidos e nem sempre se fizeram presentes nos atos iniciais das psicoterapias encetadas. Sendo assim, podemos concluir que, na maioria dos casos estudados, houve uma inversão de 


\section{ARTIGOS}

prioridades, o que acabou por interferir na continuidade das psicoterapias em questão.

\section{Referências}

Alves, R. (2008). As melhores crônicas. Campinas, SP: Papirus.

Benetti, S. P. C., \& Cunha, T. R. S. (2008). Abandono de tratamento psicoterápico: implicações para a prática clínica. Universidade do Vale do Rio dos Sinos (UNISINOS). Recuperado em 20 abr.2014 de: <http://pepsic.bvsalud.org/pdf/ $\operatorname{arbp} / \mathrm{v} 60 \mathrm{n} 2 / \mathrm{v} 60 \mathrm{n} 2 \mathrm{a} 07 . \mathrm{pdf}>$.

Campezatto, P. V. M., \& Nunes, M. L. T. (2007). Atendimento em clínicas- escola de psicologia da região metropolitana de Porto Alegre 1. Recuperado em 25 out.2014 de: $<$ http://www.scielo.br/scielo.php?script=sci_ arttext\&pid $=$ S0103166X2007000300008>.

Ceitlin, L. H. F., \& Cordioli, A. V. (2008). O início da psicoterapia. In A. V. Cordioli (Org.), Psicoterapias abordagens atuais (3. ed., pp. 125-137). Porto Alegre, RS: Artmed.

Freud, S. (1969). Esboço de psicanálise. In Edição Standard Brasileira das Obras Psicológicas Completas de Sigmund Freud (vol. XXIII, pp. 187-196). Rio de Janeiro, RJ: Imago, 1969. (Trabalho original publicado em 1938).

Freud, S. (1980). Três ensaios sobre a teoria da sexualidade. In Edição Standard Brasileira das Obras Psicológicas Completas de Sigmund Freud (vol. VII). Rio de Janeiro, RJ: Imago. (Trabalho original publicado em 1905).

Freud, S. (2010). A dinâmica da transferência. In P. C. Souza (Org.), Obras completas (vol. 10, pp. 133-146). São Paulo, SP: Companhia das Letras. (Trabalho original publicado em 1912).

Jung, S. I. (2013). Abandono em Psicoterapia Psicanalítica: estudo qualitativo. Doutorado em Medicina, Universidade Federal do Rio Grande do Sul, Porto Alegre. Recuperado em 13 abr. 2014 de: <http://www.lume.ufrgs.br/bitstream/ handle/10183/86424/000910226.pdf? sequence $=1>$.

Martins, F. (2003, jun.). Promessa e terapia. Psicologia em Revista, 9(13), 67-75.

Pereira, E. D., \& Pinto, J. P. (2003, jul./out.), Adolescência: Como se faz? apontamentos sobre discursos, corpos e processos educativos. Fazendo Gênero, Grupo Transas do Corpo, VII(17).

Searle, J. R. (1984). Os actos de fala. Coimbra: Livraria Almedina. (Trabalho original publicado em 1969).

Searle, J. R. (1995). Intencionalidade. São Paulo, SP: Martins Fontes. (Trabalho original publicado em 1983). 


\section{Resumos}

(Symbolic efficacy of promises within psychotherapy with adolescents)

By taking into account current levels of evasion from college clinics and how hard it is to lead adolescents to adhere to psychotherapy, the goal of this study is to understand whether the act of promising can contribute to linkage. To this end, we carried out exploratory, clinical method research, analyzing adolescents' speech during initial meetings. We observed that the majority of them did not establish promises. This allowed us to conclude that there are priorities to be followed at the beginning of psychotherapy.

Key words: Promise, contract, evasion, adolescence, clinic

(L'efficacité symbolique de la promesse dans la psychothérapie de l'adolescent)

Compte tenu de l'évasion observée en clinique-école et de la difficulté d'adhésion que les adolescents présentent en psychothérapie, l'objectif de cette étude est de comprendre si l'acte prometteur contribue à la liaison. Pour cela, nous avons procédé à une recherche exploratoire de la méthode clinique en analysant les actes de discours des adolescents lors des réunions initiales. On a observé que la majorité n'établissait pas l'acte prometteur. Cela nous a permis de conclure qu'il existe des priorités à suivre au début de la psychothérapie.

Mots clés: Promesse, contrat, évasion, clinique de l'adolescence

(La eficacia simbólica de la promesa en psicoterapia con adolescentes)

Considerando la evasión en la Clínica Escuela y la dificultad de adhesión que los adolescentes presentan durante la psicoterapia, la meta de este estudio es entender si el acto promisivo contribuye a la creación de un vínculo. Para ello, procedimos con una investigación exploratoria de método clínico, analizando los actos de habla de los adolescentes en encuentros iniciales. Se observó que la mayoría no estableció el acto promisivo. Lo que nos permitió concluir que existen prioridades a seguir en el comienzo de la psicoterapia.

Palabras clave: Promesa, contrato, evasión, clínica de la adolescencia

(Symbolische Wirksamkeit des Versprechens in der Psychotherapie mit Jugendlichen)

In Anbetracht der Abbruchquoten, die in den Schulkliniken festgestellt wurden, sowie der mangelnden Adhärenz von Jugendlichen in psychotherapeutischer Behandlung, untersucht diese Studie, ob ein Versprechen zum Befolgen des mit dem Therapeuten vereinbarten Behandlungsplanes beitragen könnte. Eine explorative Erforschung der klinischen Methode wurde durchgeführt, um die Sprechhandlungen 


\section{ARTIGOS}

von Jugendlichen in den ersten Sitzungen zu analysieren. Es wurde festgestellt, dass die Mehrheit von ihnen kein Versprechen ablegt und wir gelangen daher zum Schluss, dass die Erfüllung gewisser Prioritäten zu Beginn der Psychotherapie zu besseren Resultaten führen könnte.

Schlüsselwörter: Versprechen, Vertrag, Abbruchquoten, Behandlung von Jugendlichen

Citação/Citation: Vale, H. F. S. C., \& Martins, F. M. de M. C. (2017, dezembro). Eficácia simbólica da promessa em psicoterapia com adolescentes. Revista Latinoamericana de Psicopatologia Fundamental, 20(4), 641-655. http://dx.doi.org/10.1590/1415-4714.2017v20n4p641-2

Editores do artigo/Editors: Profa. Dra. Ana Maria Rudge e Profa. Dra. Sonia Leite.

Recebido/Received: 11.4.2017/ 4.11.2017 Aceito/Accepted: 15.6.2017 / 6.15.2017

Copyright: (C) 2009 Associação Universitária de Pesquisa em Psicopatologia Fundamental/ University Association for Research in Fundamental Psychopathology. Este é um artigo de livre acesso, que permite uso irrestrito, distribuição e reprodução em qualquer meio, desde que o autor e a fonte sejam citados / This is an open-access article, which permits unrestricted use, distribution, and reproduction in any medium, provided the original authors and sources are credited.

Financiamento/Funding: Os autores declaram não terem sido financiado ou apoiados. The authors have no support or funding funded to report.s

Conflito de interesses/Conflict of interest: Os autores declaram que não há conflito de interesses / The authors have no conflict of interest to declare.

\section{Hellen Fonseca de Sousa da Costa Vale}

Psicóloga Clínica; Mestre em Psicologia; Doutoranda em Psicologia pela Universidade Católica de Brasília - UCB (Brasília, DF, Br); Formação em Saúde Mental.

CAS Chácara 64 lote $03 \mathrm{~B}$

72001-590 Brasília, DF, Br

hfsousa2010@gmail.com

\section{Francisco Moacir de Melo Catunda Martins}

Psicanalista; Psiquiatra; Psicólogo; Professor emérito no departamento de Psicologia da Universidade de Brasília - UnB (Brasília, DF. Br); Professor no Programa de Pós-Graduação em Psicologia da Universidade Católica de Brasilia - UCB (Brasília, DF, Br). SHGN 715 Bloco "P”, casa 30

70770-746 Brasília, DF, Br

fracatmartins@icloud.com

This is an open-access article, which permits unrestricted use, distribution,

(c) BY-NC and reproduction in any medium for non-commercial purposes provided the original authors and sources are credited. 